\title{
PERPETRADORES DE CRÍMENES DE MASAS A LA LUZ DE LA IMAGEN.
}

\section{Perpetrators of mass crimes in the light of the image. Introduction}

\author{
Vicente Sánchez-Biosca* \\ Universitat de València
}

\author{
Lior Zylberman \\ CONICET/UNTREF/FADU-UBA (Argentina)
}

\begin{abstract}
Palabras clave
Imagen

Cine

Violencia

Genocidio

Perpetradores aporte al campo de estudio a partir del análisis de las imágenes. Asimismo, la propuesta del monográfico reside en aportar al debate sobre la temática desde, y a partir de casos de, Iberoamérica. El número cuenta con las contribuciones de Mariana Giordano, Lior Zylberman y Adriana Taboada, Eyleen Faure Bascur, Vicente Sánchez-Biosca, y Eduardo Morettin, Marcos Napolitano y Fernando Seliprandy, a las que se les suma -en la sección Papeles Críticos - los trabajos de Mariana Wikinski, Juanjo Monsell y Violeta Ros, así como una exposición online del fotógrafo guatemalteco Daniel Hernández-Salazar.
\end{abstract}

Keywords

Image

Cinema

Violence

Genocide

Perpetrators

RESUMEN: Este texto presenta el número monográfico «Perpetradores de crímenes de masas e imagen. Miradas, identidades, testimonios». El número se enmarca dentro de los uestudios sobre perpetradores", campo de investigación que se ha consolidado en los últimos años, y tiene como objetivo reflexionar en torno a la imagen; en otras palabras, ofrecer un

ABSTRACT: This text presents the monographic issue «Perpetrators of mass crimes and image. Looks, identities, testimonies". The issue is framed within "perpetrator studies", a field of research that has been consolidated in recent years. The issue aims to reflect on the image; in other words, to offer a contribution to the field of study based on the analysis of images. Likewise, the monographic issue aspires to contribute to the debate on the subject from, and based on cases from, Ibero-America. The issue features contributions by Mariana Giordano, Lior Zylberman and Adriana Taboada, Eyleen Faure Bascur, Vicente Sanchez-Biosca, Eduardo Morettin, Marcos Napolitano and Fernando Seliprandy, to which are added -in the Critical Papers section - the works of Mariana Wikinski, Juanjo Monsell, and Violeta Ros, as well as an online exhibition by Guatemalan photographer Daniel Hernandez-Salazar.

\footnotetext{
* Correspondencia a / Correspondence to: Vicente Sánchez-Biosca. Departamento Teoría de los Lenguajes y Ciencias de la comunicación, Universidad de Valencia, Avda. Blasco lbáñez 32 (46010 Valencia) - vicente.sanchez@uv.es - http://orcid.org/0000-0002-4053-4440.

Cómo citar / How to cite: Sánchez-Biosca, Vicente; Zylberman, Lior (2021). «Presentation. Perpetradores de crímenes de masas a la luz de la imagen. A modo de introducción». Papeles del CEIC, vol. 2021/2, presentación, 1-12. (http://doi.org/10.1387/pceic.23018).

ISSN 1695-6494 / (C) 2021 UPV/EHU
} 


\section{UN CAMPO DE ESTUDIOS EMERGENTE: HERENCIAS Y OBSTÁCULOS}

En 2011, en un artículo convertido ya en clásico, Richard Crownshaw (2011) constataba que en los últimos años se había producido un giro significativo hacia la figura del perpetrador en la ficción histórica literaria. Jenni Adams y Sue Vice (2013) compilaron, poco después, un libro que analizaba el perpetrador en películas y obras literarias sobre el Holocausto. En lo que a la literatura se refiere, un punto álgido estuvo representado por el éxito y las controversias que siguieron a la publicación de la extensísima novela de Jonathan Littell (2006), Les bienveillantes (Las benévolas), que fue galardonada con el premio Goncourt en 2006 y muy pronto traducida a numerosos idiomas. Pero sin duda la mayor convulsión respecto a la popularidad inquietante del perpetrador de crímenes de masas tuvo lugar en 2012 con el estreno del documental The Act of Killing de Joshua Oppenheimer ${ }^{1}$.

Las razones de la preeminencia del impacto visual sobre el literario no pueden extrañar, dado el papel cultural que el cine desempeña en el imaginario colectivo por encima de otros medios de expresión, unido a la facilidad que este discurso tiene para difundirse en un ámbito transnacional. En el caso al que nos referimos, el film venía avalado, además, por las prestigiosas figuras de Errol Morris y Werner Herzog en calidad de productores, dos cineastas y documentalistas audaces, uno de los cuales - Morris - ya era conocido por su confrontación con acusados de tortura, negacionistas y presuntos criminales de guerra, no necesariamente condenados por los tribunales, y el otro arrastrando una filmografía repleta de individuos paranoicos, delirantes y demiúrgicos. Narrado desde la perspectiva de los asesinos, el film de Oppenheimer ponía en escena algunos de los recursos más novedosos experimentados por el documental de las últimas décadas, como el re-enactment o reconstrucción de los hechos por parte de sus autores ex profeso para la cámara, y añadía a ello cuestiones que habían ocupado en años precedentes a la psicología, la psiquiatría y el psicoanálisis, como la asociación de la memoria al trauma (aplicado, sobre todo caso de las víctimas, pero que Raya Morag, precisamente en estos mismos años -2013-, aplicó a los perpetradores a partir del caso del cine israelí surgido de la Segunda Intifada). Como aliciente añadido, Oppenheimer incorporaba una serie de recursos a la vez siniestros y distanciadores como el exotismo kitsch y la autorreflexividad, muy en boga en el género documental o, más en general, en el arte contemporáneo. La suma de todos esos ingredientes favoreció el efecto del film, como si en The Act of Killing cristalizaran diversos vectores que venian anunciándose separadamente desde los años ochenta del siglo pasado y, en cualquier caso, a escala más reducida.

Valor añadido tenía el hecho de que este ejemplo -como había sucedido poco antes con el film de animación autoficcional titulado Waltz with Bashir (Ari Folman, 2008), centrado en las matanzas de palestinos en los campos de refugiados ubicados en Sabra y Shatila en 1982 por parte de falangistas cristianos libaneses con la connivencia del ejército israelí- se distanciaba de aquel banco de pruebas y canalización de los más creativos discursos sobre la violencia de masas y el genocidio que había sido el Holocausto (en materia testimonial y archivística). El objeto del film de Oppenheimer era la masacre de supuestos comunistas en Indonesia tras el confuso intento de golpe militar en 1965. Tanto en Folman como en Oppen-

La revista Film Quarterly le dedicó un monográfico en el invierno de 2013, apenas estrenado el film, con una variedad de enfoques y juicios hacia el film reveladora del shock que había producido en la comunidad cinematográfica (y no solo en ella, en realidad) (Rich, 2013). Pero ya antes Brink y Oppenheimer (2012) habian avanzado la problemática en un libro colectivo. 
heimer, la experimentación y la apuesta ética y estética de las violencias de masas ya no quedaban presas de la Shoah ni heredaban miméticamente sus recursos.

Que el fenómeno no ha hecho sino crecer irradiando en dirección a más géneros, soportes y manifestaciones lo prueba, sin ir más lejos, la obra del suizo Milo Rau, en cuyo trabajo dramático encuentran acomodo sus investigaciones sobre grandes criminales de guerra y genocidas, como Nicolae Ceaucescu (Die letzten Tage der Ceausescus, 2011) o la labor de la Radio des milles collines en promover las condiciones para el genocidio de tutsis y hutus moderados en la primavera de 1994 en Ruanda (Hate Radio, 2014). Desde que fundara su compañía teatral en 2007 hasta su condecoración con el premio teatral suizo en 2014, su labor focaliza abiertamente la problemática que planteamos. Recuérdese, por apelar a un ejemplo anterior, que el documental Das Himmler-Projekt (2000), de Romuald Karmakar, reconstruye sin retórica ni énfasis el celebérrimo discurso de Heinrich Himmler pronunciado el 4 de octubre de 1943 en Posen en el que el Reichsführer SS se dirige a sus subalternos sin ambages hablando de la aniquilación de los judios y pone sobre soporte cinematográfico escenificaciones teatrales anteriores (Knittel, 2019: 280 y ss.).

\section{UN CAMPO DE ESTUDIO CON PRECEDENTES E HISTORIA}

Deshagamos un posible equívoco. Estas manifestaciones literarias, documentales y dramáticas no resultan significativas porque las consideremos fundacionales. La historia y las ciencias sociales ya habían focalizado su atención sobre la figura del perpetrador y el acto de perpetración desde tiempo atrás. La pregunta por el mal posee una larga historia (Bernstein, 2004; Lara, 2001), pero, aun sin remontarnos a su lugar en la filosofía de Kant y Nietzsche, el estudio de los perpetradores cobra un impulso decisivo a partir de la caída del nazismo². Sin pretender exhaustividad alguna, nace en los Tribunales de Núremberg, donde la psiquiatría fue la primera disciplina que tomó a su cargo el estudio de los jerarcas nazis que estaban siendo allí juzgados (El-Hai, 2015; Goldensohn, 2004). Las entrevistas realizadas en la prisión tenían un objetivo preciso: comprobar la «anormalidad» de estas personas, si bien se llegó a la conclusión contraria, a saber, que lo que sobrevolaba allí era una pregunta primordial sobre quiénes eran estas personas. En otras palabras, la pregunta por la identidad del perpetrador emerge casi al mismo tiempo en que comienzan a gestarse, en forma embrionaria, los estudios sobre este actor. Las reflexiones de Adorno et al. (1969) sobre la personalidad autoritaria, las consideraciones sobre sociedades enfermas, anhelantes de grandes dictadores instigadores del marcaje y culpabilización de un enemigo son constantes desde entonces.

El proceso a Adolf Eichmann en Jerusalén es el siguiente hito que dará impulso al estudio sobre el perpetrador: en paralelo a las polémicas reflexiones que en 1961 hizo Hannah Arendt (2005) en torno al planificador de la deportación, ese criminal de despacho que fue Eichmann, calificándolo de "banal», el historiador Raul Hilberg (2005) daba a conocer su monumental obra sobre la burocracia nazi, basándose precisamente en las órdenes, los documentos internos y manifestando muchas reticencias a basar su investigación en los testimonios de las víctimas. La historia y la filosofía política se sumaban así a las disciplinas que pusieron su aten-

\footnotetext{
2 Puede verse un recorrido sintético en: Ferrer y Sánchez-Biosca (2019).
} 
ción en la figura de los perpetradores, del mismo modo que psicólogos preocupados por los efectos sociales, la sumisión a la autoridad y la conformidad con el grupo, tales como Stanley Milgram (2016) o Philip Zimbardo (2008), presentaron respuestas a la cuestión. Resultó de ello un verdadero progreso en los estudios sobre la perpetración de crímenes de masa. Sea como fuere, a fines del siglo xx, todavía podía afirmarse que el Holocausto no solo era el paradigma para el estudio del genocidio, sino también para cualquier otro tipo de crimen de masa. Por ello, libros como los del psiquiatra Robert Jay Lifton (2000) o del historiador Christopher Browning (2011) tenían como fin no solo describir las acciones de sus «hombres grises» sino también indagar en torno a quiénes eran. Mas Browning, cuyo libro apareció en 1992, descendía a los ejecutores ordinarios, ese eslabón más bajo de la cadena que perpetra el crimen, de manera semejante a lo que dio carta de naturaleza a la investigación procedente de la psicología social publicada en 1989 por Herbert Kelman y V. Lee Hamilton (1990) que partía de los crimenes cometidos sobre civiles indefensos por marines norteamericanos en el poblado vietnamita de My Lai en 1968, a partir de lo cual los autores reflexionaban sobre la noción de crímenes de obediencia, poniendo el acento de su perpetración en la dinámica de grupo. Tras focalizar durante años en los grandes ideólogos y luego a los organizadores que habían planeado la ejecución, la cuestión se desplazaba a las gentes corrientes para responder a la pregunta de por qué consumaron los crímenes (¿por ideología asumida?, ¿por obediencia ciega?, ¿por presión de grupo?).

Lo llamativo de la producción académica ligada al denominado giro hacia el perpetrador (perpetrator's turn) constituye a la vez un crecimiento y una complejización de las cuestiones y las variantes. Publicaciones especializadas, redes de investigación comparada y congresos $^{3}$, demuestran un despegue progresivo, pero ya inexorable, del Holocausto como parámetro e incluyen los casos de Armenia, Ruanda, Camboya, Vietnam, las dictaduras latinoamericanas, el franquismo, el Gulag, la ex Yugoslavia, entre otros, cuya diversidad es igualmente una forma de invocar esquemas comportamentales distintos. No es menos cierto que en la articulación de tales estudios se expresa, a pesar de las particularidades regionales, un imaginario transnacionalizado, impregnado de horror y fascinación a la vez, respecto a la agencia del crimen, sus enigmas y sus fantasías. A su vez, la difusión de atrocidades vía internet, ya sea debido a filtraciones - como las fotos tomadas por policías militares en la prisión de Abu Ghraib, Irak, en 2003-como a una campaña de terror - como los diversos videos de ISIS durante la década de 2010 - constituye una muestra de la ubicuidad de la imagen en nuestra era contemporánea, conviviendo así las imágenes de perpetradores con las familiares o de nuestra vida cotidiana que circulan a miles diariamente.

Last but not least, debe invocarse esa forma de viaje a través de la historia que ha marcado nuestros tiempos recientes, a saber: el turismo. La inclusión de lugares de infausto recuerdo en los circuitos, al mismo nivel que los museos o los monumentos artísticos, ha dado un nuevo empuje a las visitas a lugares del crimen y a la interrogación sobre cómo sucedieron estos. Apenas veinte años después del célebre libro sobre turismo siniestro (dark tourism) es-

3 Además de aquellos congresos que, dedicados a problemáticas históricas, genocidios, violencias de masas, abordan de manera creciente la problemática del perpetrador, vale la pena citar la creación de una red de estudios sobre perpetración -Perpetrator Studies Network - en torno a la Universidad de Utrecht (https://perpetratorstudies.sites.uu.nl), y en 2017 una revista -Journal of Perpetrator Research-, dirigida por Susanne Knittel https://jpr.winchesteruniversitypress.org). Si bien aquí también el Holocausto sigue posicionado en un lugar de preferencia (Jensen y Szejnmann, 2008), muchos son los autores que han iniciado una lectura crítica de este prioridad convertida en modelo y patrón (Straus, 2017). 
crito por Lennon y Foley (2000), las variantes del fenómeno han crecido hasta límites insospechados por sus autores.

Si observamos rápidamente algunas de las obras nodales sobre la temática publicadas en este período, veremos que el Holocausto ocupa un lugar canónico, seguido por trabajos sobre Camboya (Williams, 2020) o Ruanda (Hatzfeld, 2004). Igualmente importante es resaltar el carácter complejo de la metodología de análisis que está en la base de este giro; si bien siguen teniendo lugar investigaciones desde la psicología, la sociología o la criminología (Anderson, 2018; Mann, 2000; Waller, 2007), los diversos volúmenes colectivos editados en los últimos años dan muestra de que el estudio de los perpetradores puede ser llevado a partir de una variedad de metodologías analíticas, combinando así estudios visuales con la sociología o bien analizando obras literarias en clave histórica (Anderson y Jessee, 2020; Knittel y Goldberg, 2020; McGlothlin, 2021; Williams y Buckley-Zistel, 2018). Parte de este cruce metodológico-disciplinario lo podemos ver también en trabajos dedicados al estudio de la imagen (Morag, 2020; Sánchez-Biosca, 2016).

Si bien no aspiramos en esta introducción a presentar un detallado estado del arte, es preciso mencionar que este campo de estudio se viene desarrollando también en forma sistemática en la academia iberoamericana. El proyecto de investigación REPERCRI (Representaciones contemporáneas de perpetradores de Violencias de masas: conceptos, relatos e imágenes), con sede en la Universidad de Valencia, tiene como objetivo fomentar el estudio interdisciplinar en torno a la figura del perpetrador a través de seminarios, congresos y diversas publicaciones ${ }^{4}$. El trabajo coordinado por Claudia Feld y Valentina Salvi (2019) en torno a las declaraciones de los represores de la última dictadura militar argentina también resulta ser una exploración en este campo de estudio a partir de las particularidades que presenta el caso argentino. Finalmente, otro aporte importante al estudio de la temática en idioma español ha sido el dosier, también coordinado por Feld y Salvi, que fuera editado en Kamchatka. Revista de análisis cultural en $2020^{5}$.

\section{LA IMAGEN COMO PROBLEMA}

Decíamos que han sido los efectos culturales, artísticos y mediáticos relacionados con la problemática y el punto de vista de los perpetradores de crímenes de masas y violencia política los síntomas más reveladores de la visibilidad de esta figura en nuestras sociedades durante las últimas dos décadas. Lo sorprendente, sin embargo, es que la reflexión teórica sobre los aspectos visuales que muchas de estas manifestaciones entrañan se encuentra en un grado todavía muy elemental y precario de elaboración. $O$, por decirlo de modo más matizado, que existe una desproporción entre la vida de las imágenes en nuestra contemporaneidad y el grado de reflexión metodológica sobre ellas. Es evidente que muchos de esos productos (en fotografía, cómic, cine y televisión, sobre todo) han sido analizados por especialistas en imagen, quienes los consideraban en general como piezas individuales. También es cierto que

\footnotetext{
4 Véase la página web, www.repercri.com. Respecto a los proyectos, «Representaciones de perpetradores de violencia de masas: conceptos, relatos e imágenes» (HAR2017-83519-P) y «De espacios de perpetración a lugares de memoria. Formas de Representación» (PROMETEO/2020/059).

5 Para consultar el monográfico, véase https://ojs.uv.es/index.php/kamchatka/issue/view/1161
} 
han sido abordados por antropólogos e historiadores. Sin embargo, estos últimos han tomado el soporte visual, mayoritariamente, como una ilustración de fenómenos que su especialidad les llevaba a estudiar, mientras que los primeros lo han hecho desde la óptica de una semiótica visual con poco recorrido más allá de las fronteras de la imagen.

La idea que subyace al presente dosier se ancla en la necesidad de poner en conexión y articular dos saberes de naturaleza distinta: el conocimiento de los procesos históricos y sociales que se movilizan en una acción de violencia de masas y la competencia específica para determinar la función de la imagen en la representación de los mismos, es decir, abordar qué queda fuera de la visión, cómo se construye el relato, cuáles son las particularidades expresivas y técnicas de cada soporte de imagen. En suma, si se aspira a extraerle rendimiento, el soporte visual no puede ser entendido como transparente: muestra, revela y a la vez vela y enmascara. Sin un conocimiento específico de sus códigos, resulta imposible desentrañar su sentido, tanto como es infructuoso y empobrecedor analizar una escena de violencia con los únicos instrumentos del análisis estilístico y formal. Varios de esos elementos permiten entre ambas esferas y se encuentran, por tanto, en la base de nuestra propuesta de dosier: el punto de vista, la composición del espacio, la temporalidad y el montaje, sobre todo. Detengámonos breve y a la vez didácticamente sobre estos instrumentos.

Comencemos por el concepto de punto de vista. Este define dos cuestiones distintas: por una parte, la posición física adoptada respecto a los hechos violentos representados. En este sentido, puede decirse que la cámara adopta el punto de vista de uno de los personajes o del común denominador de los asesinos, como sucede en el caso de la primera ejecución puesta en escena por ISIS ante las cámaras que fue difundida en agosto de 2014 (la del periodista norteamericano James Foley). En ella, el dispositivo videográfico actuaba en régimen de total connivencia con el ejecutor que aparecía, junto a su víctima arrodillada, frente a la cámara. Sin embargo, la noción de punto de vista alude también a la cosmovisión ante los hechos representados; en términos más precisos, el hecho de que la identidad de posiciones implica una identificación de valores, es decir, que la cámara es cómplice del crimen o, más aún, que añade un suplemento de sufrimiento a la víctima6. Mas una tercera cuestión no debería pasar desapercibida: este modelo de filmación (o de toma fotográfica, en su caso) entraña predefinir un lugar a través del cual el espectador futuro se verá constreñido a penetrar en la escena representada; deberemos, pues, a pesar de nuestro presumible rechazo, adoptar el punto de vista físico del dispositivo de perpetración que los criminales nos asignaron. Todo ello obliga a poner en juego los instrumentos metodológicos de que disponemos para pensar la imagen, desde los elaborados por la narratología para el cine de ficción (las diferencias, por ejemplo, entre las nociones de punto de vista, focalización, perspectiva narrativa e identificación) hasta los que plantean las estrategias documentales, desde la mera observación (ese tipo de documental que Bill Nichols (2001) denominó «observacional») hasta las estrategias de continuidad y fragmentación.

Lo planteado respecto a la noción de punto de vista podría aplicarse mutatis mutandis a otros conceptos de la representación visual, aunque no actuantes por igual en todos sus formatos. Limitémonos a señalar dos de ellos: la forma del relato y el montaje. La primera -el relatodefine un orden de mostración de acontecimientos que, en lugar de sujetarse a la cronología

6 Este es el tema que se estudia desde el punto de vista metodológico y con abundantes ejemplos en SánchezBiosca (2021). Marianne Hirsch desarrolló esta diferencia a propósito de la mirada familiar (Familial Gaze) en su libro Family Frames (1997). En un texto posterior (2001: 23) aplica estos conceptos al caso de los perpetradores. 
de los mismos, es susceptible de un tratamiento por medio de elipsis, analepsis o prolepsis, es decir, a un juego con el tiempo que resulta determinante para la presentación de los actores del crimen y de sus víctimas. Pero sobre todo es decisivo porque el orden narrativo (cronológico o no) implica una serie de relaciones de causalidad, con lo cual presuponen o apuntalan una suerte de interpretación de los crímenes (no carente de ambigüedad) y de sus motivos individuales o grupales (psicológicos, psicosociales, por ejemplo). De ahí que proponer un orden en la representación del crimen (post facto, en el curso de la acción, enlazando momentos anteriores y posteriores) tiene consecuencias sobre el concepto de crimen que deseamos representar y sobre sus actores.

¿Qué hay del montaje en este contexto? Se entiende por tal, en un sentido amplio que puede aplicarse a las artes del espectáculo (teatro, circo, cine, incluso fotografía), la forma de ajustar piezas distintas que componen la representación, pues cabe que esta se organice de forma distinta a la narrativa: por coexistencia, por paralelismo, por asociación, poniendo en marcha todos los recursos propios de la poesía irracionalista (como hizo el cine de vanguardia). Estudiar el montaje de estas representaciones exportándolo al cómic, por limitarnos a un ejemplo, no solo supone concebir por qué se suceden escalas distintas de planos (primeros planos, planos generales o de conjunto, raccords, etc.), sino de qué modo la transmisión de una interpretación de los crímenes en discursos visuales es inseparable de su forma de presentación. Y el montaje, como bien sabemos, puede ser utilizado también en el interior de una imagen fija, como la fotográfica, si bien su campo de maniobras más rico reside en la imagen en movimiento.

Valgan las notas anteriores de estímulo para apuntar el encuentro que hemos tratado de dar a este dosier; un encuentro nada unívoco ni sencillo entre la imagen en cualquiera de sus formatos y la perpetración (la agencia del crimen) de los crímenes de masas en el ámbito de estudios de lberoamérica. Entre otras dificultades, dicho encuentro entraña - como dijimosuna doble competencia por parte de los autores: conocer la mecánica, el dispositivo y las consecuencias de los crímenes y saber cómo descifrar los códigos específicos de la representación visual.

\section{EL DOSIER: UN ABANICO DE CASOS EMBLEMÁTICOS}

El presente dosier surge en el marco de las interrogaciones recién planteadas. Si bien fue propuesto como una continuación de las exploraciones presentadas en el número especial que editamos los dos coordinadores en Genocide Studies and Prevention. An International Journal (Volumen 12, número 2) ${ }^{7}$, en este monográfico buscamos aportes diferentes.

En primera instancia, deseamos que este conjunto de artículos sea una contribución al campo de estudio sobre los perpetradores con el fin de pensar el análisis visual como una dimensión analítica válida desde lberoamérica, tanto como una mirada desde dicha geografía así como de los casos analizados. En otras palabras, el dosier está concebido desde la uperiferia», en el sentido de constituir un conjunto de análisis de casos que pertenecen a la "periferia del canon de los estudios sobre genocidio" y violencia en masa (Hinton, 2016).

\footnotetext{
7 Volumen 12, número 2, https://scholarcommons.usf.edu/gsp/vol12/iss2/
} 
Cada artículo del dosier presenta un abordaje singular y un estudio de caso diferente, brindando en conjunto diversas formas de ingresar en el estudio visual de los perpetradores. En esa dirección, los artículos indagan principalmente dos tipos de imágenes: la fotografía y el cine, tanto el documental como la ficción.

El dosier se abre con el artículo de Mariana Giordano, «De autores, testigos y acusados. Trayectos de construcción de la imagen como prueba en las fotografías de la Masacre indígena de Napalpí». Como señala su título, el texto interroga la masacre que tuvo lugar en la reducción indígena de Napalpi en lo que fuera el Territorio Nacional del Chaco en Argentina en el año 1924 utilizando como insumo visual para el análisis una serie de fotografías atribuidas al antropólogo alemán Robert Lehmann Nitsche. La autora analiza el rol de dichas imágenes como huella, testimonio y evidencia, prestando atención tanto a los contextos de producción y de recepción originales como a su circulación en la actualidad. Giordano sugiere que las diversas lecturas de estas fotografías dan cuenta de gestos de apropiación y recuperación identitaria a partir de los cuales se pueden revertir los regímenes de visibilidad y las memorias hegemónicas.

El segundo artículo lleva como título «La retórica edad-impunidad en los juicios por los crímenes cometidos durante el genocidio argentino (1975-1983)" y sus autores son Lior Zylberman y Adriana Taboada. En este artículo también se toma la fotografía como material de estudio siendo el objetivo analizar lo que los autores denominan la "retórica edad-impunidad» en el marco de los juicios de lesa humanidad que tienen lugar en la Argentina desde 2006. Por dicha retórica, que da lugar a una «impunidad gerontológica», los autores entienden la estrategia llevada adelante tanto por las defensas en los juicios como en ciertos sectores de la sociedad - como el diario argentino La Nación - con el objetivo de que los acusados logren no ser juzgados, o bien que sus penas sean más leves u obtener prisión domiciliaria. Para llevar adelante el análisis de las imágenes, el artículo trabaja con la dialéctica visto-no visto a través de fotografías y editoriales del mencionado diario, siendo los principales puntos de anclaje teórico el concepto de "viejismo" aportado por la gerontología y la "fórmula del martirio" que surge del estudio de las representaciones de masacres y genocidios desarrollado por José Emilio Burucúa y Nicolás Kwiatkowski. De este modo, los autores observan cómo los perpetradores se autoperciben y buscan ser percibidos como víctimas, eximiéndose en consecuencia de culpa y responsabilidad.

«El victimario como sujeto de dolor. La figurabilidad del perpetrador en la película documental chilena "El Mocito"» escrito por Eyleen Faure Bascur, es el tercer artículo del dosier. En él, la autora trabaja sobre la última dictadura militar de Chile a partir de la película documental dirigida por Jean de Certeau y Marcela Said. Valiéndose de un marco teórico que se asienta en diversos aspectos del cine documental, la película, sugiere la autora, se inserta en el giro hacia el perpetrador en las producciones culturales que se ha dado en ese país durante la última década. El texto sostiene que la película elabora una representación del victimario - de Jorgelino Vergara, "el mocito», quien en su juventud sirvió de mozo en cuarteles de detención de la DINA y la CNI- que, por estar centrada en la vulnerabilidad extrema del sujeto, elude la cuestión de su responsabilidad. La película ofrece así, según su análisis, un retrato naturalista, que se enfoca en los estragos que el régimen habría producido en la vida de Vergara. De modo similar a como hace el texto anterior de este dosier, el artículo analiza la manera en que el victimario se percibe como víctima.

«Por sus obras los conoceréis. Documentos de perpetrador y voces de víctimas en Retratos de identificação (Anita Leandro, 2014)», escrito por Vicente Sánchez-Biosca, es el cuarto ar- 
tículo del dosier. El documental de Leandro, nacido como una investigación histórica, se propone reescribir mediante el uso de la composición y el montaje los documentos visuales y materiales de los perpetradores del primer caso de tortura difundido públicamente en Brasil en 1969. Gran parte de las fotografías que emplea el documental son analizadas y pensadas, según el autor del artículo, como «imágenes de perpetrador» ya que encarnan la mirada de quienes planeaban las acciones violentas a la vez que tipificaban la imagen de un enemigo. De este modo, a partir de la puesta en diálogo entre estas fotografías, films militantes de los años setenta y otras instantáneas y documentos con testimonios registrados en el presente, Sánchez-Biosca piensa la obra de Leandro en línea con la de realizadores como Harun Farocki - Chris Marker, quienes con sus películas han logrado interrogar y analizar las imágenes por medio de las imágenes mismas.

El quinto y último artículo del dosier es «El perpetrador en el cine brasileño: genealogía de un personaje (1979-2007)", escrito por Eduardo Morettin, Marcos Napolitano y Fernando Seliprandy. En él, los autores analizan cómo se ha ido construyendo y tratando como personaje la figura del torturador en el cine ficcional brasileño durante el período en cuestión. Dicha figura fue un actor importante en el marco del aparato represivo estatal que se instauró a partir de la dictadura brasileña que tuvo lugar entre los años 1964 y 1985. En la genealogía que propone el artículo, los autores trazan un diálogo entre las películas del corpus, su contexto histórico y las diversas estrategias de memoria social del período. Desde esa perspectiva, las películas elegidas para el análisis se dividen en dos bloques: por un lado, aquellas que fueron producidas todavía en dictadura; por el otro, las realizadas a partir de la década de 1990 cuando Brasil era ya un régimen democrático. De este modo, las películas del primer período sugieren el posible vínculo entre la policía y la estructura represiva de la dictadura, tensionando y problematizando así la histórica separación entre violencia política y violencia policial ante crimenes comunes. En cambio, respecto a las películas del segundo período, los autores sugieren que forman parte de cierto revisionismo conservador que postula a la dictadura como una reacción a la lucha armada de izquierda y que sirve para justificar la violencia actual en la resolución de conflictos políticos y sociales.

Finalmente, se publican tres papeles críticos y un trabajo fotográfico vinculado con la temática del dosier. La primera reseña, escrita por Mariana Wikinski, examina el libro Las voces de la represión. Declaraciones de perpetradores de la dictadura argentina editado por Claudia Feld y Valentina Salvi. Fruto de una investigación colectiva e interdisciplinaria, el libro presenta diversos textos donde se analizan las declaraciones públicas de diversos represores argentinos, sus condiciones de posibilidad, sus marcas de interpretación como sus contenidos y efectos entre otros tópicos. A continuación, Juanjo Monsell escribe sobre el libro El infierno de los perpetradores. Imágenes, relatos y conceptos, editado por Anacleto Ferrer y Vicente Sánchez-Biosca. Luego de brindar un recorrido por los diversos capítulos, la reseña destaca el valor académico de la publicación ya que ofrece un análisis multidisciplinario de la figura del perpetrador tanto en su dimensión monstruosa como en su banalidad humana. La sección concluye con la reseña escrita por Violeta Ros que tiene como fin revisar el documental El silencio de otros (Almudena Carracedo y Robert Bahar, 2018). Este documental surge del acompañamiento a algunas personas en la llamada querella argentina contra los crímenes del franquismo para exponer así una síntesis del estado actual del problema de la memoria en España. La propuesta crítica sobre el documental que plantea la autora parte de la representación de la víctima y su trauma para llegar a la problemática de los perpetradores y cómo esta cuestión ha comenzado a permear el cine de ficción (o recreación histórica) español. 
Cierra el presente número una exposición online del fotógrafo guatemalteco Daniel Hernández-Salazar cuyas instantáneas fueron tomadas durante el juicio por Genocidio al General Efraín Ríos Montt. Como expresa el fotógrafo en el texto que acompaña las imágenes, estas fotografías resumen de forma simbólica lo que ese proceso representó para la historia de Guatemala. Estas fotografías, afirma Hernández-Salazar, son un testamento y un homenaje para los protagonistas de la búsqueda de justicia por la barbarie sobrevivida en aquel país. Mediante esta serie de imágenes que recogen sobre el juzgamiento de un perpetrador, creemos que resulta la forma más potente de concluir el presente número especial, pues la obra del fotógrafo -en el acto fotográfico que implica mirar, cortar, contextualizar el instante de un cuadro mucho más amplio- adquiere un papel de radiografía y relato condensado, además de poseer ese valor performativo que, a su manera, cambia la realidad.

\section{REFERENCIAS BIBLIOGRÁFICAS}

Adams, J., y Vice, S. (Eds.). (2013). Representing Perpetrators in Holocaust Literature and Film. Portland: Vallentine Mitchell.

Adorno, Th., Frenkel-Brunswick, E., Levinson, D., y Nevitt-Sanford, R. (1969[1950]). The Authoritarian Personality. Nueva York: Norton \& Co.

Anderson, K. (2018). Perpetrating genocide. A criminological account. Nueva York: Routledge.

Anderson, K., y Jessee, E. (Eds.). (2020). Researching perpetrators of genocide. Madison: University of Wisconsin Press.

Arendt, H. (2005). Eichmann en Jerusalén. Barcelona: Debolsillo.

Bernstein, R.J. (2004). El mal radical. Una indagación filosófica. Buenos Aires: Lilmod.

Brink, J.T., y Oppenheimer, J. (Eds.) (2012). Killer Images. Documentary Film, Memory and the Performance of Violence. Londres y Nueva York: Wallflower.

Browning, C. (2011). Aquellos hombres grises. El batallón 101 y la solución final en Polonia. Barcelona: Edhasa.

Crownshaw, R. (2011). Perpetrator Fictions and Transcultural Memory. Parallax, 17(4), 75-89.

El-Hai, J. (2015). El nazi y el psiquiatra. Barcelona: Ariel.

Feld, C., y Salvi, V. (Eds.). (2019). Las voces de la represión. Declaraciones de perpetradores de la dictadura argentina. Buenos Aires: Miño y Dávila.

Ferrer, A., y Sánchez-Biosca, V. (2019). En una selva oscura. Introducción al estudio de los perpetradores. En A. Ferrer y V. Sánchez-Biosca (Eds.), El infierno de los perpetradores: Conceptos, imágenes y relatos (pp. 13-51). Barcelona: Bellaterra.

Goldensohn, L. (2004). The Nuremberg interviews: An American psychiatrist's conversations with the defendants and witnesses. Nueva York: Vintage Books.

Hatzfeld, J. (2004). Una temporada de machetes. Barcelona: Anagrama.

Hilberg, R. (2005). La destrucción de los judíos europeos. Madrid: Akal. 
Hinton, A. (2016). Estudios críticos sobre genocidio. Revista de Estudios sobre Genocidio, 11, 13-26.

Hirsch, M. (1997). Family Frames. Photography, Narrative, and Postmemory. Cambridge y Londres: Harvard University Press.

Hirsch, M. (2001). Surviving Images: Holocaust Photographs and the Work of Postmemory. The Yale Journal of Criticism, 14(1), 5-37.

Jensen, O., y Szejnmann, C.-C.W. (Eds.). (2008). Ordinary people as mass murderers: Perpetrators in comparative perspectives. Nueva York: Palgrave Macmillan.

Kelman, H., y Lee Hamilton, V. (1990). Crimenes de obediencia. Barcelona: Planeta.

Knittel, S.C. (2019). Ante los perpetradores: repetición, reeenactment, representación. En A. Ferrer y V. Sánchez-Biosca (Eds.), El infierno de los perpetradores: Conceptos, imágenes y relatos (pp. 273-296). Barcelona: Bellaterra.

Knittel, S.C., y Goldberg, Z.J. (Eds.) (2020). The Routledge international handbook of perpetrator studies. Abingdon: Routledge.

Lara, M.P. (Ed.) (2001). Rethinking Evil. Contemporary perspectives. Berkeley: University of California Press.

Lennon, J., y Foley, M. (2000). Dark Tourism. The Attraction of Death and Disaster. Cornwall: Continuum.

Lifton, R.J. (2000). The Nazi Doctors. Nueva York: Basic Books.

Littell, J. (2006). Les bienveillantes. París: Gallimard.

Mann, M. (2000). Were the perpetrators of Genocide «Ordinary Men» or «Real Nazis»? Results from Fifteen Hundred Biographies. Holocaust and Genocide Studies, 14(3), 331-366.

McGlothlin, E. (2021). The Mind of the Holocaust Perpetrator in Fiction and Nonfiction. Detroit: Wayne State University Press.

Milgram, S. (2016). Obediencia a la autoridad. El experimento Milgram. Madrid: Capitan Swing.

Morag, R. (2013). Waltzing with Bashir. Perpetrator Trauma and Cinema. Bloomsbury: I.B. Tauris.

Morag, R. (2020). Perpetrator cinema: Confronting genocide in Cambodian documentary. Londres y Nueva York: Wallflower Press.

Nichols, B. (2001). Introduction to Documentary. Bloomington \& Indianapolis: Indiana University Press.

Rich, R. (Ed.) (2013). Special Issue «The Act of Killing». Film Quarterly, 67(2).

Sánchez-Biosca, V. (2016). Modos de mirar, actos de matar. Miradas desde el nuevo siglo. En R. Cueto (Ed.), The Act Of Killing. Cine y violencia global (pp. 11-24. San Sebastián: Donostia Kultura.

Sánchez-Biosca, V. (2021). La muerte en los ojos. Qué perpetran las imágenes de perpetradores. Madrid: Alianza. 
Straus, S. (2017). Studying Perpetrators: A Reflection. Journal of Perpetrator Research, 1(1), 28-38.

Waller, J. (2007). Becoming Evil. How Ordinary People Commit Genocide and Mass Killing. Nueva York: Oxford University Press.

Williams, T. (2020). The Complexity of Evil. Perpetration and Genocide. New Brunswick: Rutgers University Press.

Williams, T., y Buckley-Zistel, S. (Eds.) (2018). Perpetrators and Perpetration of Mass Violence. Action, Motivations and Dynamics. Nueva York: Routledge.

Zimbardo, P. (2008). El efecto Lucifer. Barcelona: Paidós. 